\title{
REPERCUSSÕES DA DEPRESSÃO PÓS-PARTO NO DESENVOLVIMENTO INFANTIL
}

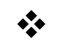 \\ Luísa Parreira Santos \\ Universidade Federal do Triângulo Mineiro - UFTM - Brasil \\ Conceição Aparecida Serralha \\ Universidade Federal do Triângulo Mineiro - UFTM - Brasil
}

\begin{abstract}
Resumo
O presente trabalho tem como objetivo apresentar uma revisão da literatura científica nacional sobre as repercussões para o desenvolvimento emocional, social, comportamental e cognitivo do bebê, em contexto de depressão puerperal materna. Nesta revisão, foram recuperados trabalhos segundo os seguintes critérios de inclusão: artigos científicos de periódicos indexados, com publicação entre 2006 e 2012, no idioma português e que correlacionassem depressão pós-parto e desenvolvimento infantil. Foram excluídos livros, capítulos, notícias, resenhas, dissertações, teses, monografias, artigos com publicação anterior a 2005, trabalhos em idiomas estrangeiros e artigos que tratassem da depressão pós-parto somente em seus aspectos etiológicos. Foi observado que a depressão pós-parto é um fator de risco para o desenvolvimento infantil, pois os bebês que viveram tal contexto apresentam apego inseguro, menos exploração do ambiente, sono irregular, baixa autoestima, ansiedade e maior probabilidade de desenvolverem depressão na idade adulta. É essencial que o transtorno seja identificado para que a mãe e o bebê recebam cuidado profissional adequado, minimizando os prejuízos da depressão pós-parto para ambos e para a família.
\end{abstract}

Palavras-chave: depressão pós-parto, depressão puerperal, interação mãe-bebê.

\section{Introdução}

A depressão pós-parto (DPP) é um transtorno emocional puerperal que afeta tanto a saúde da mãe quanto a saúde do seu filho. Além dela, outros transtornos podem ocorrer no período do 
pós-parto, ou puerpério, como o baby blues e a psicose puerperal. Assim, faz-se necessário caracterizar cada transtorno separadamente tendo em vista que os sintomas são semelhantes.

O baby blues é um quadro passageiro caracterizado por hiperemotividade, estado de fragilidade, sentimentos de falta de confiança e de incapacidade para cuidar do bebê. É considerado um quadro leve e transitório, que atinge cerca de $60 \%$ das mães entre o terceiro e o quinto dia após o parto, tendo remissão espontânea (SCHWENGBER; PICCININI, 2003). Catão (2002) aponta que tal período é necessário para que a mãe perceba que seu bebê e ela são indivíduos separados, marcando o fim da gravidez psíquica. A psicose pós-parto, por sua vez, é um transtorno grave e raro, no qual são notados sintomas como agitação psicomotora, angústia, insônia, confusão mental, pensamentos delirantes com relação ao bebê e, em casos extremos, está altamente relacionado ao infanticídio (FRIZZO; PICCININI, 2005; SCHIMIDT; PICCOLOTO; MÜLLER, 2005).

A manifestação do quadro de depressão pós-parto acontece geralmente a partir das primeiras quatro semanas após o nascimento do bebê, alcançando sua intensidade máxima durante os seis primeiros meses posteriores (MORAES et al., 2006). Ela atinge de 10\% a $20 \%$ das mães em pelo menos uma gravidez e, em aproximadamente um terço destas, persiste por toda a vida (MENDES; LOUREIRO; CRIPPA, 2008). Os sintomas mais comuns são desânimo persistente, irritabilidade, choro frequente, ansiedade, sentimentos de culpa, distúrbios do sono, ideias suicidas, temor de machucar o filho, autoacusação, redução do apetite e da libido, perda do prazer nas atividades cotidianas e ocorrência de ideias obsessivas (SANTOS JUNIOR; SILVEIRA; GUALDA, 2009; SILVA; SANCHES, 2008).

Sua etiologia não é claramente conhecida, mas vários fatores podem contribuir para seu surgimento, como relação conflituosa com o cônjuge, não desejo ou não planejamento da gravidez, abandono do parceiro, baixa escolaridade, baixo nível socioeconômico, histórico familiar de transtornos de humor, tempo de encontro com o bebê após o parto, eventos estressantes durante a gestação, frustração quanto ao papel de mãe, sentimentos de negação à criança e baixa autoestima (MORAES et al., 2006; SANTOS JUNIOR; SILVEIRA; GUALDA, 2009). As mães deprimidas também sofrem grande influência de suas próprias expectativas, podendo sentir-se preocupadas por não conseguirem ser a mãe ideal que esperavam, ou sentiremse frustradas por notarem que sua vida como mãe não é como elas imaginavam (SILVA; SANCHEZ, 2008). 
O nascimento de um filho é um acontecimento de grande repercussão na vida da mulher e dos familiares, exigindo mudanças em vários aspectos para absorver o novo membro na dinâmica e na rotina da casa. A alegria e a satisfação pela chegada do filho se chocam com as responsabilidades de assumir novas tarefas e limitações de algumas atividades anteriores (SILVA; SANCHEZ, 2008). Desde o nascimento, quando o bebê é incapaz de sobreviver sem ajuda, até a maturidade, a principal fonte de referência da criança são as pessoas que a circundam. De acordo com Mattos (1988), o ser humano tem a necessidade de vivenciar situações que favoreçam seu desenvolvimento emocional para garantir o amadurecimento em cada fase do seu crescimento. Embora o apoio de toda a família seja essencial para oferecer uma rede de cuidados saudáveis ao bebê, para Winnicott (1990) a mãe é a pessoa mais indicada para se adaptar às necessidades dele, porque estas são expressas de uma maneira que exigem tal sutileza de entendimento, que apenas a mãe biológica possui, uma vez que todas as condições gestacionais, quando vividas dentro da normalidade, facilitam esse processo de identificação da mãe com o bebê. Winnicott (1978) nomeou essa capacidade de a mãe se identificar com o seu filho de "Preocupação Materna Primária", que se inicia durante a gestação e, em condições normais, deve dissipar-se poucas semanas após o nascimento do bebê.

A qualidade das relações precoces entre o bebê e sua mãe permite o desenvolvimento do apego, que é um vínculo recíproco e duradouro entre o bebê e seu cuidador (Papalia, Olds \& Feldman, 2007). Bowlby (1988), ao desenvolver a teoria do apego, descreveu que a saúde mental da criança depende de uma relação calorosa e íntima com sua mãe, ou uma substituta permanente dela. Spitz (1979, p. 125), por sua vez, afirmou que “[...] o maior grau de facilitação para as ações do bebê é propiciado, não pelas ações conscientes da mãe, mas por suas atitudes inconscientes". Para este pesquisador, a relação mãe-bebê é mantida por vínculos afetivos extremamente poderosos, constituindo a base de segurança do bebê e o protótipo de relacionamento que ele irá aplicar na construção de relacionamentos com outras pessoas. Compreensivelmente, as mães que vivenciam uma depressão pós-parto significativa interagem de forma diferente com seus bebês se comparadas às mães emocionalmente saudáveis e de humor mais normal (BEE, 2003). A mãe deprimida geralmente é menos sensível e se envolve menos com seu bebê, é menos capaz de responder ao choro dele, suas interações são menos positivas e são menos propensas a fazer comentários sobre o estado mental da criança, segundo afirmam Papalia, Olds e Feldman (2007). As consequências dessa situação no bebê, descritas por estas autoras, incluem a desistência de 
enviar sinais emocionais à mãe, apresentação de apego inseguro, preferência por tarefas que exijam poucos desafios, menor motivação e propensão maior a desenvolver depressão na vida adulta.

Outra questão de importância acerca do desenvolvimento do bebê em contexto de depressão materna são os efeitos da vida intra-uterina para a saúde infantil. Segundo Loreto (2008), pode haver maior influência dos acontecimentos pré-natais na saúde física e emocional do feto do que de fatores genéticos. Os estados afetivos da mãe, seus sentimentos e emoções se comunicam com o feto através da ação dos neuro-hormônios. A pesquisadora mostrou em seus estudos que emoções positivas da mãe produzem no feto respostas como aumento da frequência cardíaca e, do mesmo modo, emoções negativas como temor, angústia e depressão produzem perturbações emocionais e alterações fisiológicas. Mães que vivem em constante estresse produzem maior quantidade de cortisol, que altera o cérebro tornando-o vulnerável a processos que destroem neurônios. O estresse causa endurecimento da artéria uterina, fazendo com que a irrigação sanguínea na placenta seja menor e o feto receba menos nutrição, desenvolvendo-se, portanto, menos que o normal (BUSNEL; PEDROMÔNICO, 2002). Isto pode gerar no bebê recém-nascido comportamentos ditos depressivos, como pouca ou nenhuma expressão de interesse, menos excitabilidade, sono irregular, choro constante e elevadas taxas de cortisol (LORETO, 2008). A autora também ressalta que tais características são notadas logo no pósparto, antes que haja interações suficientes entre o bebê e sua mãe para justificá-las. A literatura apresenta dados que revelam que bebês de mães deprimidas tendem a apresentar padrões incomuns de atividade cerebral, como menor atividade na região frontal esquerda associada a emoções como alegria e raiva, e maior atividade na área frontal direita, que controla emoções como aflição e desgosto, assim como maiores níveis de hormônios do estresse (PAPALIA; OLDS; FELDMAN, 2007).

As atitudes do próprio bebê dirigidas à mãe também podem ser consideradas desencadeadoras ou agravadoras da depressão materna. De acordo com Gesell (1985), a criança constantemente inquieta poderá deixar a mãe nervosa e perturbada, ao passo que a criança calma tende a deixar a mãe mais tranquila e satisfeita. $\mathrm{O}$ agravamento do quadro depressivo pode ocorrer se o bebê, a despeito dos esforços e cuidados da mãe, não demonstrar satisfação ou não transmitir emoções positivas, intensificando sentimentos de incapacidade por parte dela. 
Nos estudos sobre a paternidade no contexto de depressão pós-parto, de Silva e Piccinini (2009), foram encontrados quatro principais aspectos sobre o papel dos pais: proteção à saúde mental da mãe, proteção à saúde mental do bebê, relação entre o relacionamento conjugal e ocorrência da depressão puerperal e participação do pai na dinâmica familiar. Os pesquisadores concluíram que a participação do pai nas famílias em que a mãe apresenta depressão pós-parto é de fundamental importância, pois ele fornece apoio material e emocional à mãe, transmite segurança a ela, auxilia nos cuidados com o bebê, e seu envolvimento pode, inclusive, atenuar os efeitos do transtorno no desenvolvimento da criança. A participação do pai configura-se como um fator de proteção à saúde da criança, pois ele seria capaz de oferecer cuidados substitutos e de criar interações mais positivas e de melhor qualidade com seu filho. Não obstante, a qualidade da relação conjugal pode ser uma fonte de descontentamento e insatisfação para a mãe, tendo em vista que o pai pode não oferecer o apoio que ela necessita e espera. Sousa, Prado e Piccinini (2011) destacam que mães deprimidas apresentam maior ocorrência de representações negativas sobre a maternidade, como, entre outros fatores, o sentimento de ser pouco apoiada pelo companheiro. Em concordância, Prado, Piovanoti e Vieira (2007) apontam que a ausência ou deficiência do pai podem gerar consequências negativas para a mãe e ser um gatilho para a depressão materna.

Na pesquisa de Mendes, Loureiro e Crippa (2008), que correlacionou depressão materna e saúde mental de crianças em idade escolar, foram encontradas evidências de que crianças de mães deprimidas apresentam mais problemas de comportamento, maior risco para transtornos mentais em comparação a crianças filhas de mães normais, estilo de regulação emocional passivo, dificuldade em distrair sua atenção, presença de psicopatologias como ansiedade e comportamentos disruptivos, prejuízos para o autoconceito como atribuições negativas a respeito de si mesmas e dificuldades no desempenho social.

A partir do exposto e da compreensão da relevância da depressão pós-parto como fator de risco para o desenvolvimento infantil, considerou-se importante uma revisão do que tem sido investigado e publicado no Brasil sobre o tema, o que gerou o presente artigo. 


\section{Objetivo}

Apresentar uma revisão da literatura científica nacional sobre as repercussões para o desenvolvimento emocional, social, comportamental e cognitivo do bebê do contexto de depressão puerperal materna, bem como possíveis prejuízos à relação mãe-bebê.

\section{Método}

\section{Instrumentos}

Para realização da presente revisão de literatura, procedeu-se à busca de trabalhos nacionais indexados por meio de consulta às bases de dados LILACS (Literatura LatinoAmericana e do Caribe em Ciências da Saúde), SciELO (Scientific Eletronic Library Online) e PePsic (Periódicos Eletrônicos em Psicologia). Os descritores utilizados, de acordo com o Vocabulário de Termos em Psicologia e os Descritores em Ciências da Saúde (DeCS), foram: depressão pós-parto, depressão puerperal e interação mãe-criança.

\section{Critérios de Inclusão}

Foram definidos como critérios de inclusão para este estudo: artigos científicos de periódicos indexados com texto integral, abrangência do período de publicação entre os anos de 2006 e 2012, restrição ao idioma português e correlação entre depressão pós-parto e desenvolvimento infantil e interação mãe-bebê.

\section{Critérios de Exclusão}

Os critérios de exclusão estabelecidos foram: estudos como teses, monografias, dissertações, notícias, livros, capítulos de livros, resenhas, artigos com publicação anterior ao ano de 2006, em idiomas estrangeiros e que tratassem da depressão pós-parto em seus aspectos etiológicos e sintomatológicos, ou sobre tratamentos com psicofármacos.

\section{Procedimento}

Inicialmente, os descritores depressão pós-parto, depressão puerperal e interação mãecriança foram inseridos nas caixas de pesquisa avançada das bases de dados LILACS, SciELO e PePsic para uma busca geral de trabalhos relacionados ao tema. Devido ao elevado número de 
trabalhos encontrados, 139 no total, a primeira amostra foi selecionada com base na leitura dos títulos e compôs-se de 31 trabalhos. Posteriormente, procedeu-se a uma leitura atenta dos resumos para selecionar os trabalhos que mais se adequassem ao tema e aos objetivos desta revisão, reduzindo o número a 22. Concluída esta etapa, foram aplicados os critérios de inclusão e exclusão estabelecidos previamente e a amostra final resumiu-se ao número de 9 artigos, sendo 4 encontrados por meio do SciELO, 3 provenientes da LILACS e 2 provenientes da PePsic. Tais artigos foram recuperados na íntegra entre os dias 1 e 9 de fevereiro de 2013 para leitura completa do conteúdo, fichamento, análise sistemática e comparação.

\section{Resultados}

Na Tabela 1 foram relacionados os resultados obtidos ao final do procedimento de busca.

Tabela 1 - Relação dos resultados do procedimento de busca

\begin{tabular}{l|c|c|c}
$\begin{array}{l}\text { Bases de } \\
\text { Dados }\end{array}$ & $\begin{array}{c}\text { Trabalhos } \\
\text { encontrados }\end{array}$ & $\begin{array}{c}\text { Trabalhos } \\
\text { selecionados }\end{array}$ & $\begin{array}{c}\text { Trabalhos } \\
\text { recuperados }\end{array}$ \\
\hline LILACS & 88 & 19 & 3 \\
\hline SciELO & 43 & 9 & 4 \\
\hline PePSIC & 9 & 3 & 2
\end{tabular}

Após leitura completa dos textos e análise dos artigos recuperados, eles foram listados e organizados na Tabela 2, contendo o nome completo dos artigos, o nome dos autores, a instituição onde o estudo foi conduzido e produzido, o ano de publicação e o tipo de pesquisa.

Tabela 2 - Identificação dos artigos selecionados

\begin{tabular}{l|c|c|c|c|c}
\hline $\mathrm{N}^{\mathbf{0}}$ & Título do Artigo & Autores & Instituição & Ano & $\begin{array}{c}\text { Tipo de } \\
\text { Estudo }\end{array}$ \\
\hline 1 & As implicações da depressão & Freitas, L. V., & Universidade de São & 2012 & \\
& pós-parto na psique do bebê: & Scarabel, C. Al, & Paulo (USP) & & $\begin{array}{c}\text { Discussão } \\
\text { Teórica }\end{array}$ \\
& $\begin{array}{c}\text { Considerações da Psicologia } \\
\text { Analítica }\end{array}$ & Duque, B. H. & & & \\
& & & & &
\end{tabular}




\begin{tabular}{|c|c|c|c|c|c|}
\hline 2 & $\begin{array}{l}\text { Depressão Materna e sua } \\
\text { repercussão na relação inicial } \\
\text { mãe-bebê }\end{array}$ & Teixeira, G. F. & $\begin{array}{c}\text { Contemporâneo - } \\
\text { Instituto de } \\
\text { Psicanálise e } \\
\text { Transdisciplinaridade }\end{array}$ & 2007 & $\begin{array}{l}\text { Revisão de } \\
\text { Literatura }\end{array}$ \\
\hline 3 & $\begin{array}{l}\text { Dialogia mãe-filho em } \\
\text { contextos de depressão materna: } \\
\text { revisão de literatura }\end{array}$ & $\begin{array}{l}\text { Carlesso, J. P. } \\
\text { P., Suza, A. P. } \\
\text { R. }\end{array}$ & $\begin{array}{c}\text { Universidade Federal } \\
\text { de Santa Maria } \\
\text { (UFSM) }\end{array}$ & 2011 & $\begin{array}{l}\text { Revisão de } \\
\text { Literatura }\end{array}$ \\
\hline 4 & $\begin{array}{l}\text { Maternidade e depressão: } \\
\text { impacto na trajetória de } \\
\text { desenvolvimento }\end{array}$ & $\begin{array}{c}\text { Alt, M. S., } \\
\text { Benetti, S. P. C. }\end{array}$ & $\begin{array}{c}\text { Pontifícia } \\
\text { Universidade } \\
\text { Católica do Rio } \\
\text { Grande do Sul (PUC- } \\
\text { RS) }\end{array}$ & 2008 & $\begin{array}{l}\text { Relato de } \\
\text { Caso }\end{array}$ \\
\hline 5 & $\begin{array}{l}\text { O impacto da depressão } \\
\text { materna nas interações iniciais }\end{array}$ & $\begin{array}{l}\text { Brum, E. H. M., } \\
\text { Schermann, L. }\end{array}$ & $\begin{array}{c}\text { Universidade } \\
\text { Luterana do Brasil } \\
\text { (ULBRA) }\end{array}$ & 2006 & $\begin{array}{l}\text { Revisão de } \\
\text { Literatura }\end{array}$ \\
\hline 6 & $\begin{array}{l}\text { A depressão materna e suas } \\
\text { vicissitudes }\end{array}$ & Brum, E. H. M & $\begin{array}{c}\text { Universidade } \\
\text { Luterana do Brasil } \\
\text { (ULBRA) }\end{array}$ & 2006 & $\begin{array}{l}\text { Relato de } \\
\text { Caso }\end{array}$ \\
\hline 7 & $\begin{array}{l}\text { Depressão puerperal e interação } \\
\text { mãe-bebê: um estudo piloto }\end{array}$ & $\begin{array}{l}\text { Ramos, S. H. A. } \\
\text { S., Furtado, E. F. }\end{array}$ & $\begin{array}{c}\text { Universidade de São } \\
\text { Paulo } \\
\text { (USP) }\end{array}$ & 2007 & $\begin{array}{c}\text { Pesquisa } \\
\text { Quantitativa }\end{array}$ \\
\hline 8 & $\begin{array}{l}\text { Relação entre depressão pós- } \\
\text { parto e disponibilidade } \\
\text { emocional materna }\end{array}$ & $\begin{array}{l}\text { Fonseca, V. R. J. } \\
\text { R. M., Silva, G. } \\
\text { A., Otta, E. }\end{array}$ & $\begin{array}{c}\text { Universidade de São } \\
\text { Paulo } \\
\text { (USP) }\end{array}$ & 2010 & $\begin{array}{c}\text { Pesquisa } \\
\text { Quantitativa }\end{array}$ \\
\hline 9 & $\begin{array}{l}\text { Depressão } \quad \text { pós-parto em } \\
\text { puérperas: } \\
\text { interações entre mãe, filho e } \\
\text { família }\end{array}$ & $\begin{array}{c}\text { Silva, F. C. S., } \\
\text { Araújo, T. M., } \\
\text { Araújo, M. F. } \\
\text { M., Carvalho, C. } \\
\text { M. L., Caetanos } \\
\text { J. A. }\end{array}$ & $\begin{array}{c}\text { Universidade Federal } \\
\text { do Ceará } \\
\text { (UFC) }\end{array}$ & 2010 & $\begin{array}{c}\text { Pesquisa } \\
\text { Qualitativa }\end{array}$ \\
\hline
\end{tabular}


Como demonstrado na Tabela 2, 4 dos artigos escolhidos são revisões de literatura, 2 são pesquisas quantitativas, 1 é pesquisa qualitativa e 2 são relatos de caso. Foi evidenciada também, a grande quantidade de trabalhos produzidos no Rio Grande do Sul, provindos da Universidade Federal do Rio Grande do Sul, da Pontifícia Universidade Católica do Rio Grande do Sul e da Universidade Luterana do Brasil.

Com relação aos objetivos, a Tabela 3 lista os objetivos gerais e específicos de cada artigo da forma como foram descritos pelos próprios autores.

Tabela 3 - Objetivos gerais e específicos dos artigos selecionados

\begin{tabular}{|c|c|c|}
\hline & Objetivo Geral & Objetivos Específicos \\
\hline 1 & $\begin{array}{l}\text { Apresentar e comentar a contribuição que a } \\
\text { Psicologia Analítica, criada por Carl Gustav } \\
\text { Jung, traz como subsídio teórico nesse } \\
\text { campo, aproximando sua compreensão da } \\
\text { relação mãe-bebê à questão da depressão } \\
\text { pós-parto, buscando sanar em parte a } \\
\text { escassez de estudos a esse respeito na } \\
\text { Psicologia Analítica. }\end{array}$ & \\
\hline 2 & $\begin{array}{l}\text { Revisar alguns estudos relevantes sobre a } \\
\text { interação mãe-bebê em situação de } \\
\text { depressão materna e as consequências } \\
\text { emocionais no bebê e no seu } \\
\text { desenvolvimento futuro. }\end{array}$ & \\
\hline 3 & $\begin{array}{l}\text { Verificar as repercussões da depressão } \\
\text { materna na interação mãe-filho e examinar } \\
\text { suas implicações para o desenvolvimento da } \\
\text { criança, especialmente o de linguagem. }\end{array}$ & \\
\hline 4 & $\begin{array}{l}\text { Discutir a trajetória de uma mulher que } \\
\text { apresentou um quadro depressivo grave no } \\
\text { primeiro ano de vida de sua filha e reviveu } \\
\text { esses sintomas quando esta ingressou na } \\
\text { puberdade. }\end{array}$ & \\
\hline
\end{tabular}




\begin{tabular}{|c|c|c|}
\hline 5 & $\begin{array}{l}\text { Examinar questões teóricas a respeito da } \\
\text { depressão materna, em particular o impacto } \\
\text { da depressão materna nas interações iniciais } \\
\text { para o desenvolvimento infantil. }\end{array}$ & \\
\hline 6 & $\begin{array}{l}\text { Alertar sobre o impacto da depressão } \\
\text { materna no desenvolvimento infantil. }\end{array}$ & $\begin{array}{l}\text { Refletir sobre esse impacto e sobre os caminhos } \\
\text { possíveis para dirimir suas consequências a partir } \\
\text { do referencial teórico da psicoterapia psicanalítica. }\end{array}$ \\
\hline 7 & $\begin{array}{l}\text { Comparar perfis de interação mãe-bebê } \\
\text { entre mães deprimidas e não deprimidas no } \\
\text { terceiro mês do pós-parto. }\end{array}$ & $\begin{array}{l}\text { Avaliar e comparar os perfis de interação mãe-bebê } \\
\text { entre mães com depressão no pós-parto e mães que } \\
\text { não apresentavam esta condição, focalizando as } \\
\text { consequências para o funcionamento psicossocial } \\
\text { da criança. }\end{array}$ \\
\hline 8 & $\begin{array}{l}\text { Determinar a prevalência da depressão pós- } \\
\text { parto, comparar a interação mãe-bebê nos } \\
\text { grupos com e sem depressão e verificar a } \\
\text { relação entre depressão, apoio social e } \\
\text { estilos de relacionamento e disponibilidade } \\
\text { emocional materna. }\end{array}$ & $\begin{array}{l}\text { - Avaliar a prevalência de sintomas depressivos } \\
\text { entre o segundo e quarto mês após o parto; } \\
\text { - Investigar a qualidade da interação diádica mãe- } \\
\text { bebê na presença de depressão materna em } \\
\text { comparação com ausência de depressão, utilizando } \\
\text { filmagens na sala de parto e em laboratório; } \\
\text { - Investigar as relações entre a qualidade da } \\
\text { interação mãe-bebê e os dados referentes ao estilo } \\
\text { de relacionamento da mãe e ao apoio social; } \\
\text { - Investigar as relações entre depressão pós-parto e } \\
\text { apoio social percebido pela mãe e entre depressão } \\
\text { pós-parto e estilo de relacionamento da mãe. }\end{array}$ \\
\hline 9 & $\begin{array}{l}\text { Conhecer a interação de puérperas que } \\
\text { apresentam depressão pós-parto com seus } \\
\text { filhos e compreender a percepção de } \\
\text { familiares sobre a doença e os cuidados } \\
\text { maternos prestados por essas puérperas. }\end{array}$ & \\
\hline
\end{tabular}

Os artigos identificados pelos números 1, 2, 3, 5, 7 e 8 objetivaram, no geral, analisar aspectos conceituais da depressão pós-parto como fatores de risco e prevalência, e o impacto dessa condição para o desenvolvimento do bebê e para a interação mãe-bebê. Além destas questões, o artigo 9 se preocupou em apontar as impressões e percepções das mães deprimidas 
sobre seu desempenho como mãe e a ajuda do parceiro, considerando sua subjetividade. O artigo número 6 procurou, além de caracterizar o transtorno e seus efeitos, apontar possíveis medidas para diminuir suas consequências no desenvolvimento do bebê. O artigo 4, por sua vez, buscou discutir os impactos da depressão pós-parto no desempenho do papel materno ao longo do crescimento da criança.

Os principais resultados obtidos em cada artigo estão relacionados a seguir.

Tabela 4 - Principais resultados encontrados em cada artigo

\begin{tabular}{l|l}
\hline & \multicolumn{1}{c}{ Principais Resultados } \\
\hline 1 & $\begin{array}{l}\text { Uma relação conturbada entre a mãe e seu filho, o não suprimento das demandas físicas e } \\
\text { emocionais do bebê e a indisponibilidade da mãe em contexto de depressão puerperal podem } \\
\text { gerar no bebê o sentimento de insegurança, abandono, insaciedade e desconfiança. Podem } \\
\text { provocar reações compensatórias no bebê, a formação de um ego negativizado e de um self } \\
\text { fragilizado, sentimentos de culpa e de sabotagem à própria personalidade, além de poder } \\
\text { desencadear neuroses e psicoses devido ao desenvolvimento precoce do ego. Experiências } \\
\text { negativas na relação mãe-bebê podem ainda provocar no adulto a sensação de que não podem } \\
\text { confiar em nada e de serem rejeitados, levando a dificuldades de relacionamento. }\end{array}$ \\
\hline 2 & $\begin{array}{l}\text { A depressão pós-parto só tem impacto para o bebê quando atinge a interação com a mãe. A falta } \\
\text { de responsividade da mãe tem sido relacionada a baixo nível de interesse em pessoas e objetos ao } \\
\text { final do primeiro ano de vida do bebê, assim como levar a um desligamento gradual da mãe e à } \\
\text { microdepressão, em que se observa desaparecimento da animação, deflação da postura, } \\
\text { diminuição do afeto positivo e da expressão facial, evitação do olhar. Em decorrência do estilo } \\
\text { interativo da mãe, o bebê pode desenvolver um estilo de interação deprimido com baixo padrão } \\
\text { de atividade e apatia ou comportamentos hiperativos com irritação e grandes níveis de ansiedade. }\end{array}$ \\
\hline 3 & $\begin{array}{l}\text { Crianças de mães deprimidas têm 29\% mais chances de desenvolver desordens emocionais e } \\
\text { comportamentais que crianças de mãe não deprimidas. De modo geral, os resultados demonstram } \\
\text { que crianças de mães deprimidas podem apresentar interação mais pobre com suas mães, menos } \\
\text { vocalizações, mais desvio do olhar, sinais de angústia, irritação, choro por mais tempo, menor } \\
\text { comportamento exploratório, percentil de peso mais baixo, comportamento depressivo, } \\
\text { preferência por rostos tristes, menos cooperação, autoimagem negativa, distúrbio de apego, maior } \\
\text { incidência de diagnóstico psiquiátrico e maior risco de alterações da atividade cerebral, }\end{array}$ \\
\hline
\end{tabular}


$4 \quad$ A história de vida da paciente em questão é marcada por eventos traumáticos que deixaram falhas importantes no seu psiquismo e suas vivências depressivas foram revividas com o nascimento da filha. Ela sentia desejo de matá-la e projetava na filha sua agressividade, frustração e sentimento de abandono. A maternidade exigiu da paciente um investimento afetivo maior do que sua disponibilidade, evidenciando graves distúrbios no vínculo com a filha.

5 As crianças filhas de mães deprimidas são expostas a uma maior probabilidade de desenvolverem psicopatologias posteriores. Os prejuízos ao desenvolvimento do bebê ocorrem na medida em que os sintomas depressivos impedem a mãe de se conectar ao seu filho. Na literatura pesquisada, evidencia-se que os bebês de mães deprimidas apresentam redução da atividade cerebral frontal região associada a expressão de afetos positivos, maior incidência de depressão na infância, mais dificuldades de relacionamento, menos competência social, alteração na capacidade de controle egóico e baixo escore para resiliência.

6 A ausência emocional da mãe da paciente, que sofria de depressão maior e posteriormente de depressão pós-parto crônica, levou à constituição de um falso self que encobria defensivamente o self verdadeiro, pesadelos de morte constantes, sintomas depressivos e forte vivência de desamparo e sofrimento, além da dificuldade em existir como filha frente à uma mãe que demandava cuidados. A paciente refere que a história de desamparos se repete em sua família por três gerações, o que evidencia o peso histórico da psicopatologia.

7 A depressão pós-parto foi correlacionada significativamente com redução da qualidade de interação mãe-bebê, podendo afetar a formação de vínculo e a comunicação da díade. Falhas na reparação de erros de comunicação podem levar o bebê a experienciar afetos negativos, dificuldades em exploração do ambiente e interação social, senso de desamparo e desconfiança.

8 Não foi encontrada associação estatisticamente significativa entre a depressão pós-parto e as demais variáveis de disponibilidade emocional materna; nem entre as médias nas escalas de disponibilidade emocional e sexo do bebê, ocupação da mãe, residir com o companheiro, planejamento da gestação e ter desejado o bebê. A qualidade da interação entre mãe e bebê não foi diferente nos grupos de mães com e sem depressão, sugerindo que a depressão pós-parto não afete amplamente os bebês aos quatro meses. Mães deprimidas que apresentaram maior sensibilidade são mais estruturantes, menos intrusivas e hostis e seus bebês são mais responsivos.

9 As principais alterações emocionais relatadas pelas participantes foram o choro fácil, nervosismo e tristeza, condições que as incapacitam para suas atividades maternas e afetam toda a família, em graus variados. Dessa forma, o auxílio à puérpera é bastante relevante para o desenvolvimento psicossocial da criança. 
De modo geral, os artigos 2, 3, 5, 6, 7 e 9 chegaram a resultados semelhantes: a etiologia da depressão pós-parto é multifatorial, ela afeta negativamente o desenvolvimento do bebê em diferentes aspectos e a qualidade do cuidado que a mãe oferece, a gravidade e tempo de duração dos sintomas são fatores de risco para o desenvolvimento saudável do bebê no aspecto emocional, cognitivo e social, o pai tem papel fundamental no apoio à mulher e sua presença é um fator de proteção para o bebê e, por fim, as crianças de mães deprimidas apresentam maior probabilidade de desenvolverem psicopatologias na adolescência e/ou vida adulta.

Os estudos identificados pelos números 4 e 9 somaram informações ao coletarem relatos subjetivos de mães deprimidas, apontando que elas se perceberam incapazes, insatisfeitas, frustradas, inseguras, estressadas, confusas quanto às suas emoções, sensíveis a conflitos familiares e indicaram o apoio do cônjuge e da família como fator de proteção, embora pouco tenham discutido sobre os efeitos do quadro depressivo para o bebê. É importante ressaltar que um dos resultados trazidos pelo artigo 9 é justamente o desconhecimento dos familiares sobre a depressão pós-parto da mulher. Resultados semelhantes foram encontrados nos artigos 7 e 8, que assinalam que as mães deprimidas reagem de forma mais inadequada ao choro dos seus bebês, possuem menos prontidão para a comunicação, menor exatidão na percepção deles e maior necessidade de apoio.

Os artigos de número 1 e 2 ressaltaram a importância do apoio familiar e social à mãe deprimida, tanto em assistência a ela quanto na oferta de cuidados adequados e interações positivas com o bebê. $\mathrm{O}$ estudo de número 3 traz as mesmas considerações acerca do impacto da depressão pós-parto, apontando a idade da criança, seu temperamento, a cronicidade do quadro e o estilo interativo da mãe como elementos vinculados à sua intensidade.

Por fim, os artigos 2, 4, 5 e 6 trouxeram possibilidades de intervenção precoce para a mãe e para o bebê, a fim de reduzir os efeitos negativos da depressão pós-parto para ambos e para a família. $\mathrm{O}$ artigo 1 destaca a importância do tratamento farmacológico em alguns casos e a igual ou superior importância do tratamento psicológico simultaneamente.

\section{Discussão}

Os artigos recuperados e analisados nos permitem notar a grande influência que o comportamento da mãe tem sobre seu bebê, tanto durante a gravidez quanto na qualidade dos cuidados oferecidos após o nascimento. O bebê recém-nascido é um ser completamente 
dependente e a confiança que adquire no mundo se dá por intermédio dos cuidados, da estimulação e atenção que recebe. A partir de algumas semanas de desenvolvimento intrauterino, os órgãos sensoriais permitem que o bebê reconheça estímulos externos, como sons e sabores. Essas experiências são importantes para os primeiros contatos afetivos entre a mãe e seu filho (Ferraz, 2012). Sendo assim, ao nascer e se deparar com um ambiente completamente desconhecido é de crucial importância que a mãe esteja bem para apresentar o mundo ao seu bebê de uma forma não intrusiva.

A análise também demonstrou que a depressão pós-parto influencia negativamente a maneira como a mãe se organiza para cuidar do seu bebê, apresentando geralmente um estilo de cuidado e interação considerados inadequados e não saudáveis, principalmente se a depressão for intensa e se estender por muito tempo.

Em nossa cultura é esperado que a mãe ame incondicionalmente seu filho, que saiba como cuidar dele e que tenha paciência o tempo todo. Além disso, a própria mãe idealiza o seu filho e a nova etapa que está por iniciar. Como citado anteriormente (MORAES et al., 2006; SANTOS JUNIOR; SILVEIRA; GUALDA, 2009; SILVA; SANCHEZ, 2008), as expectativas podem gerar ansiedade e frustração na mulher, caso ela não consiga atendê-las, não fique satisfeita com seu desempenho como mãe ou se desiluda de forma abrupta quanto ao filho, configurando assim um fator de risco para seu bem-estar emocional. O artigo 3 apresenta que a preferência pelo sexo da criança e ter pensado em interromper a gravidez guardam relação com o quadro depressivo. Os resultados obtidos no artigo 8 , de certa forma, discordam de tais afirmativas e da literatura consultada, ao não encontrarem relação significativa entre disponibilidade emocional da mãe e ter desejado ou planejado a gravidez.

O estudo de número 4 aponta que, no puerpério, a mulher revive e reelabora sua relação enquanto filha com seus pais e que o nascimento do bebê pode desencadear, na mãe, conflitos e lutos mal-elaborados da infância. O artigo 1 esclarece, à luz da Psicologia Analítica, que o complexo materno, formado pelas experiências com figuras cuidadoras e ligadas ao Arquétipo da Grande Mãe, é ativado na gestação e permeará seu relacionamento com o bebê. Dessa forma, se a mãe consolidou um complexo materno com polaridade negativa, ela terá dificuldades para se relacionar de forma saudável com seu bebê. No relato de caso número 4 , o autor diz que sua paciente não conseguia oferecer um cuidado adequado e um investimento afetivo saudável à filha porque ela mesma não havia recebido isto de sua mãe, a seu tempo. O mesmo é dito no artigo 
número 6 , em que a mãe sentia que tinha pouco a oferecer para sua filha porque não recebeu muitos recursos de sua mãe.

Entende-se que os profissionais de saúde precisam questionar a extensão dos prejuízos desse quadro tanto para o bom desenvolvimento da criança quanto para as interações familiares. Não há evidências que comprovem que as dificuldades de relação entre uma mãe deprimida e seu filho se repitam em diferentes gerações da família, mas os estudos revelam a importância da qualidade dos cuidados iniciais para a saúde emocional da criança, uma vez que, de acordo com o artigo 1, o que acontece nos primeiros anos deixa marcas por todo o desenvolvimento.

Embora, culturalmente, a mãe seja a cuidadora principal e a maior parte das responsabilidades para com o bebê recaia sobre ela, alguns autores apontam que há formas de compensar as vivências negativas que a criança possa ter em decorrência das dificuldades da mãe deprimida. $\mathrm{O}$ artigo número 1 sugere que o bebê tenha contato com elementos que lhe deem algum tipo de amparo com relação ao arquétipo da Grande Mãe, como jardins ou árvores, e que lhe sejam oferecidas mais experiências positivas que negativas. Contudo, isso só é possível caso as experiências negativas não tenham ocorrido na fase mais precoce da vida da criança. A teoria Winnicottiana, em contrapartida, esclarece que um bebê precisa de relações interumanas, necessitando, portanto, de um substituto materno humano.

A compensação pode ser feita, assim, pela rede de apoio da mãe e a presença do cônjuge foi citada como essencial nos artigos 2 e 9. Quando o pai é participativo, sua presença media o contato entre a mãe e o bebê e pode amenizar os efeitos negativos da depressão da mãe, configurando um fator de proteção para ambos. Foi confirmado, por meio dos relatos das mães participantes, que os bebês vocalizam mais e apresentam expressões mais positivas quando interagem com seus pais do que quando interagem com as mães. Os resultados do artigo número 8 mostraram que maior apoio social durante a gestação está relacionado a sintomas depressivos mais leves no puerpério.

O bebê precisa sentir segurança nos cuidadores para apresentar comportamentos de exploração e receber respostas de encorajamento dos pais. Tais conclusões reafirmam o que disse Mahler (1982) sobre a importância da confiança no ambiente. Completando essa idéia, o artigo 5 apontou que resultados adversos sobre o bebê ocorrem na medida em que o estado da mãe impede que ela se identifique com ele. Isto vai ao encontro da teoria de Winnicott, que revela que uma mãe que não se encontra bem emocionalmente, pode não conseguir entrar no estado de 
Preocupação Materna Primária, essencial para a identificação da mãe com o seu bebê. A interação da díade, nesses casos, geralmente se caracteriza por comportamentos intrusivos ou retraídos por parte da mãe, embora não tenha sido possível concluir qual o impacto real do estilo de interação apático e do intrusivo separadamente. Em concordância, o artigo 2 cita que o quadro depressivo da mãe só tem impacto para o bebê quando a interação mãe-bebê é afetada. Em síntese, os sintomas da depressão pós-parto que a mãe venha a apresentar podem não afetar negativamente o desenvolvimento do bebê se a mãe conseguir interagir minimamente com o seu bebê, assim como receber apoio para realizar as tarefas com as quais não consiga lidar.

$\mathrm{O}$ artigo 8 ressalta em seus resultados que não houve correlação estatisticamente significativa entre disponibilidade emocional e a depressão pós-parto, mas houve correlação entre disponibilidade emocional e responsividade do bebê. Também houve correlação entre apoio social e responsividade do bebê e entre apoio social e estruturação da mãe. Tais resultados indicam que mais importante que a depressão puerperal que a mãe está vivenciando é a qualidade da relação que ela vai estabelecer com seu bebê e como ela se organiza para atender às necessidades físicas e emocionais dele. Dessa forma, é crucial que essa mãe seja acolhida em seu sofrimento e que seus recursos sejam avaliados para além dos sintomas do quadro depressivo.

Os artigos de número 2 e 9, além de reafirmarem as informações sobre a etiologia da depressão pós-parto como associada a muitas variáveis, informaram que mães deprimidas agem de forma indecisa, confusa e às vezes insensível com seus bebês e apresentam visão negativa quanto às mudanças do bebê. Este, por sua vez, tende a se envolver menos com pessoas e objetos, seu comportamento pode se tornar apático ao tentar se identificar e imitar a mãe, e pode apresentar olhar evitativo e menos expressões de interesse.

A idade na qual o bebê se encontra parece ser um fator importante para a interação, a partir dos resultados obtidos no artigo 8, que sugere que os bebês aos quatro meses não são amplamente afetados pela depressão pós-parto. Em contrapartida, o estudo número 3 cita que bebês de 2 meses de idade de mães deprimidas apresentaram menor grau de afeto positivo e de expressão emocional, tendendo a desenvolver distúrbios de comportamento - em especial o de sono - até aproximadamente um ano e meio de idade, mesmo que aos três meses as mães tenham superado a depressão.

Motta, Lucion e Manfro (2005) salientam que há um período ideal para aquisição de informações sociais, afetivas e cognitivas, porque o cérebro está pronto para formar sinapses que 
registrem as primeiras experiências da criança. Os autores citam que a falta ou insuficiência de estímulos adequados nos primeiros meses podem contribuir para a diminuição ou não formação de sinapses neuronais apropriadamente. Retomando o artigo 1, que diz que compensação arquetípica só será possível se as experiência negativas não tiverem ocorrido na fase mais precoce da vida, embora os autores não especifiquem a duração deste período considerado precoce, é possível pensar que os dois primeiros meses de vida certamente estão incluídos nesse período. Os estudos analisados não permitem concluir se a depressão puerperal afeta os bebês antes dos 2 meses de idade, e nem de que forma se daria este impacto, sendo necessários mais estudos que visem compreender esta relação e quais fatores estão envolvidos nela.

O artigo número 6, um estudo de caso, apresentou a história de uma mulher, filha de mãe deprimida, que procurou ajuda psicoterapêutica após muitos anos de resistência. A autora apontou que a falta de apoio da família à mãe da paciente foi extremamente significativa para o quadro desta. Isso confirma mais uma vez a dificuldade dos familiares em identificar o transtorno e encaminhar a mulher para ajuda profissional, o que também foi abordado no artigo 9. Segundo ela, quanto antes uma intervenção for feita menores serão os danos para a mãe, para o bebê e para toda a família em que estão inseridos. Os artigos 1, 2, 3 e 4 também enfatizaram a importância do olhar atento do profissional e do acompanhamento das gestantes e de seus companheiros desde os primeiros meses da gravidez. Os profissionais da área da saúde precisam manter a curiosidade pelas pessoas que atendem, pois, de uma investigação mais sensível e atenta a uma informação que parece trivial, questões críticas podem emergir e aclarar um contexto de sofrimento não declarado.

\section{Considerações Finais}

A partir do exposto, não se pode ignorar os inúmeros prejuízos que a criança em contexto de depressão puerperal materna sofre e que eles podem ser fatores determinantes de problemas na idade escolar e adulta, quando em casos graves. O estilo de interação que a mãe deprimida estabelece com seu filho parece ser mais crítico para o desenvolvimento dele do que o transtorno em si, pois é certo que a depressão materna altera o padrão considerado normal para a interação mãe-bebê. $O$ estabelecimento do vínculo afetivo na díade é essencial para um bom desenvolvimento do bebê, pois este é completamente dependente do ambiente no atendimento às suas necessidades físicas e emocionais. 
Contudo, o grau dos efeitos negativos sobre o bebê depende da idade dele, da gravidade do transtorno da mãe e da qualidade da maternagem que ela oferece, fatores que podem sofrer influência de outros fatores de risco, agravando o impacto da depressão puerperal, como pouco ou nenhum apoio da família e do parceiro, dificuldades socioeconômicas e eventos estressantes durante a gestação e durante o puerpério. $\mathrm{O}$ apoio familiar e social é de fundamental importância para auxiliar a mãe em suas fragilidades e no fortalecimento de seus recursos para lidar com o bebê.

Dessa maneira, é da maior importância que o quadro seja identificado em seu início para que a mãe receba o devido tratamento e acompanhamento por uma equipe de saúde e por seus familiares, a fim de que ela consiga oferecer maternagem e cuidado suficientes para o desenvolvimento saudável do seu bebê. Esforços em todos os níveis devem ocorrer também para identificar contextos em que já é sabido que há uma alta probabilidade de a depressão se desenvolver, no intuito de que sejam oferecidos cuidados que diminuam as chances do desenvolvimento da doença.

Tendo em vista a amplitude do tema, pesquisas futuras podem abranger mais informações analisando a literatura internacional, a fim de ampliar o conhecimento sobre o assunto e tentar preencher lacunas que os artigos desta revisão deixaram ou não esclareceram.

\title{
REPERCUSSIONS OF POSTPARTUM DEPRESSION ON CHILD DEVELOPMENT
}

\begin{abstract}
This work aims to present a review of the scientific literature on the domestic repercussions for the emotional, social, behavioral and cognitive development baby on the context of maternal postpartum depression. In this review, papers were recovered according to the following inclusion criteria: scientific articles in indexed journals, having published between 2006 and 2012 in Portuguese and correlating postpartum depression and child development. Were excluded books, chapters, news, reviews, dissertations, theses, monographs, articles with publication prior to 2005, works in foreign languages and articles that treat postpartum depression only in their etiological aspects. It was observed that postpartum depression is a risk factor for child development because babies who have lived this context exhibit insecure attachment, less environmental exploration, irregular sleep, low self-esteem, anxiety and more likely to develop depression in adulthood. It is essential that the disorder is identified for the mother and baby receive appropriate professional care, minimizing the losses of postpartum depression for both and for the family.
\end{abstract}


Keywords: postpartum depression, puerperal depression, mother-infant interaction

\section{REPERCUSIÓNES DE LA DEPRESIÓN POSPARTO EN EL DESARROLLO INFANTIL}

\section{Resumén}

Este trabajo tiene como objetivo presentar una revisión de la literatura científica sobre las repercusiones para el desarollo emocional, social, cognitivo y de comportamento del bebé en el contexto de la depresión posparto materna. En esta revisión, los documentos fueron recuperados de acuerdo con los siguientes criterios de inclusión: artículos científicos en revistas indexadas, después de haber publicado entre 2006 y 2012, en portugués y en la correlación de la depresión post-parto y el desarrollo del niño. Fueron excluidos los libros, capítulos, noticias, reseñas, tesinas, tesis, monografías, artículos con publicación antes de 2005, las obras en lenguas extranjeras y artículos que tratan la depresión posparto sólo en sus aspectos etiológicos. Se observó que la depresión posparto es un factor de riesgo para el desarrollo del niño, porque los bebés que han vivido este contexto exposición apego inseguro, exploración ambiental menor, sueño irregular, baja autoestima, ansiedad y más propensos a desarrollar depresión en la edad adulta . Es esencial que el trastorno se identifica para la madre y el bebé reciben atención profesional adecuada, minimizando las pérdidas de la depresión posparto para ambos e para la família.

Palabras clave: depresión posparto, depresión postparto, interacción madre-hijo.

\section{Referências}

ALT, M. S.; BENETTI, S. P. C. Maternidade e depressão: impacto na trajetória de desenvolvimento. Psicologia em Estudo, Maringá, v. 13, n.2, p. 389-394, abr./jun., 2008. Disponível em: http://dx.doi.org/10.1590/S1413-737220080002000222. Acesso em 01.02.2013.

BEE, H. A criança em desenvolvimento. 9. ed. Porto Alegre: Artmed, 2003.

BOWLBY, J. Cuidados maternos e saúde mental. São Paulo: Martins Fontes, 1988.

BRUM, E. H. M. A depressão materna e suas vicissitudes. Psychê, São Paulo, v.10, n.19, p. 95108, set/dez, 2006.

BRUM, E. H. M.; SCHERMANN, L. O impacto da depressão materna nas interações iniciais. PSICO, Porto Alegre, v. 37, n. 2, p. 151-158, maio/ago, 2006.

BUSNEL, M. C.; PEDROMÔNICO, M. Relação mãe-feto: visão atual das neurociências. São Paulo: Casa do Psicólogo, 2002. 
CARLESSO, J. P. P.; SOUZA, A. P. R. Dialogia mãe-filho em contextos de depressão materna: revisão de literatura. CEFAC, São Paulo, v. 13, n. 6, p. 1119-1126, nov./dez., 2011.

CATÃO, I. A tristeza das mães e seus riscos para o bebê. In: CORREIA-FILHO, L.; CORRÊA, M. E.; FRANÇA, P. S. Novos olhares sobre a gestação e a criança até os 3 anos: saúde perinatal, educação e desenvolvimento do bebê. Brasília: LGE Editora, p. 221-231, 2002.

FERRAZ, A. P. Estímulos intrauterinos proporcionam relação afetiva entre pais e bebê. [online] 2012. Disponível em: http://www.blog.saude.gov.br/estimulos-intrauterinos-proporcionamrelacao-afetiva-entre-pais-e-bebe/. Acesso em: 14.04.2013.

FONSECA, V. R. J. R. M.; SILVA, G. A.; OTTA, E. Relação entre depressão pós-parto e disponibilidade emocional materna. Cadernos de Saúde Pública, Rio de Janeiro, v. 26 n. 4, p. 738-746, abril, 2010. Disponível em: http://dx.doi.org/10.1590/S0102-311X2010000400016. Acesso em 03.02.2013.

FREITAS, V. L.; SCARABEL, C. A.; DUQUE, B. H. As implicações da depressão pós-parto na psiquê do bebê: Considerações da Psicologia Analítica. Psicologia Argumento, Curitiba, v. 30, n. 69, p. 253-263, abr./jun., 2012.

FRIZZO, G. B.; PICCININI, C. A. Interação mãe-bebê em contexto de depressão materna: aspectos teóricos e empíricos. Psicologia em Estudo, Maringá, v. 10, n. 1, p. 47-55, jan./abr., 2005.

GESELL, A. A criança do 0 aos 5 anos. 6. ed. São Paulo: Martins Fontes, 1985.

LORETO, V. Cuidados no início da vida: clínica, instituição, pesquisa e metapsicologia. São Paulo: Casa do Psicólogo, 2008.

MAHLER, M. Sobre a simbiose humana e as vicissitudes da individuação. Porto Alegre: Artes Médicas, 1982.

MATTOS, E. T. B. Desenvolvimento psicossocial da criança: abordagem pediátrica e psicológica. São Paulo: Sarvier, 1988.

MENDES, A. V.; LOUREIRO S. R.; CRIPPA, J. A. S. Depressão materna e saúde mental de escolares. Revista de Psiquiatria Clínica, São Paulo, v. 35, n. 5, p. 178-186, nov./dez., 2008. Disponível em: http://dx.doi.org/10.1590/S0101-60832008000500002. Acesso em 08.02.2013.

MORAES, I. G. S. et. al. Prevalência da depressão pós-parto e fatores associados. Revista de Saúde Pública, São Paulo, v. 40, n. 1, p. 65-70, ago., 2006. Disponível em: http://dx.doi.org/10.1590/S0034-89102006000100011. Acesso em 08.02.2013.

MOTTA, M. G.; LUCION, A. B.; MANFRO G. G. Efeitos da depressão materna no desenvolvimento neurobiológico e psicológico da criança. Revista de Psiquiatria do Rio Grande do Sul, Rio Grande do Sul, v. 27, n. 2, p. 165-176, maio/ago., 2005. Disponível em: http://dx.doi.org/10.1590/S0101-81082005000200007. Acesso em 05.02.2013. 
PAPALIA, D. E.; OLDS, S. W.; FELDMAN, R. D. Desenvolvimento Humano. 10. ed. Porto Alegre: AMGH Artmed, 2009.

RAMOS, S. H. A. S.; FURTADO, E. F. Depressão puerperal e interação mãe-bebê: um estudo piloto. Psicologia em Pesquisa, Juiz de Fora, v. 1, n. 1, p. 20-28, jan/jun, 2007.

SANTOS JUNIOR, H. P. O.; SILVEIRA, M. F. A.; GUALDA, D. M. R. Depressão pós-parto: um problema latente. Revista Gaúcha de Enfermagem, Porto Alegre, v. 30, n. 3, p. 516-524, set./dez., 2009.

SCHMIDT, E. B.; PICCOLOTO, N. M.; MÜLLER, M. C. Depressão pós-parto: fatores de risco e repercussões no desenvolvimento infantil. Psico-USF, Itatiba, v. 10, n. 1, p. 61-68, jan./jun., 2005. Disponível em: http://dx.doi.org/10.1590/S1413-827120050001000088. Acesso em 01.02.2013.

SCHWENGBER, D. D., \& PICCININI, C. A. O impacto da depressão pós-parto para a interação mãe-bebê. Estudos de Psicologia, Natal, v. 8, n. 3, p. 403-411, set./ dez, 2003. Disponível em: http://dx.doi.org/10.1590/S1413-294X20030003000077. Acesso em 03.02.2013.

SILVA, F. C. S. et. al. Depressão pós-parto em puérperas: conhecendo as interações entre mãe, filho e família. Acta Paulista de Enfermagem, São Paulo, v. 23, n. 3, p. 411-416, jun., 2010. Disponível em: http://dx.doi.org/10.1590/S0103-210020100003000166. Acesso em 03.02.2013.

SILVA, M. R.; PICCININI, C. A. Paternidade no contexto da depressão pós-parto materna: revisando a literatura. Estudos de Psicologia, Rio Grande do Norte, v. 14, n. 1, p. 5-12, jan./abr., 2009. Disponível em: http://dx.doi.org/10.1590/S1413-294X2009000100002. Acesso em 09.02.2013.

SILVA, V. V. P.; SANCHEZ, M. B. L. M. Depressão pós-parto: Fator prejudicial no vínculo mãe-bebê, [online]. Disponível em: http://www.algosobre.com.br/psicologia/depressao-posparto-fator-prejudicial-no-vinculo-mae-bebe.html. Acesso em 18.12.2012.

SOUZA, D. D.; PRADO, L. C.; PICCININI, C. A. Representações acerca da maternidade no contexto da depressão pós-parto. Psicologia: Reflexão e Crítica, Porto Alegre, v. 24, n. 2, p. 335343, jan./abr., 2011. Disponível em: http://dx.doi.org/10.1590/S0102-79722011000200015. Acesso em 05.02.2013.

SPITZ, R. A. O primeiro ano de vida. 3. ed. São Paulo: Martins Fontes, 1979.

TEIXEIRA, G. F. Depressão materna e sua repercussão na relação inicial mãe-bebê. Contemporânea - Psicanálise e Transdisciplinaridade, Porto Alegre, n. 2, p. 300-309, abr./jun., 2007.

WINNICOTT, D. W. Da pediatria à psicanálise. Rio de Janeiro: Imago, 2000.

WINNICOTT, D. W. Natureza Humana. Rio de Janeiro: Imago, 1990. 
Data de recebimento: 04/07/2013

Data de aceite: 07/09/2015

\section{Sobre as autoras:}

Luísa Parreira Santos é Mestranda do Programa de Pós-Graduação em Psicologia da Universidade Federal do Triângulo Mineiro. Endereço eletrônico: luisa_ps@ymail.com

Conceição Aparecida Serralha é Professora adjunta da Universidade Federal do Triângulo Mineiro, mestre e doutora em Psicologia Clínica pela Pontifícia Universidade Católica de São Paulo. Endereço eletrônico: serralhac@ hotmail.com.br 